\title{
A Model to Measure the Service Quality of Pharmaceutical Wholesalers
}

\author{
Christo A Bisschoff, Heinrich C Barnard \\ NWU Business School, North-West University, Potchefstroom, South Africa \\ Christo.bisschoff@nwu.ac.za
}

\begin{abstract}
The study constituters a model to measure the service quality of pharmaceutical wholesalers in South Africa. Several pharmaceutical wholesalers distribute medical supplies throughout South Africa in a very regulated and competitive market where high service quality levels are anticipated. In this priceundifferentiated market, service quality can have a significant impact on the competitiveness of a pharmaceutical wholesaler. As a result, the primary objective was to develop a model to measure the service quality levels of large pharmaceutical wholesalers. The literature study compiled an industry profile of the South African pharmaceutical market, analysed service quality and then proposed an adapted SERVQUAL model to measure the service quality. A review of the literature also highlighted the general structure of the pharmaceutical industry and the regulatory framework in the supply of pharmaceutical products. The literature study also focuses specifically on the role and function of the pharmaceutical wholesaler in the supply chain. Data was collected from clients of a pharmaceutical wholesaler using to record the service expectations and perceptions on a seven-point Likert scale. Some 385 of the 4468 clients completed and returned the industry-adapted SERVQUAL survey questionnaires on the electronic platform Google Forms (signifying an 8.6\% response rate). The results showed that the data were reliable with a Cronbach alpha coefficient higher than 0.70 . The results also show that in five, the service dimensions gap where perceptions and expectations are measured had negative gaps. This means that the clients expected better service quality than what they received. The service dimension Assurance showed the largest gap, while Tangibility had the smallest gap. However, none of these gaps was practically significant. Further analysis using exploratory factor analysis identified three underlying service quality variables, namely Positive employee actions, Business process management and Marketing channels. These factors explained a favourable cumulative variance of $67.7 \%$. The study finally proposes a model to measure service quality in the pharmaceutical wholesale industry.
\end{abstract}

Keywords: Service quality, pharmaceutical wholesaler, customer satisfaction, loyalty, healthcare, medicine.

\section{Introduction}

South African pharmaceutical wholesalers service all the healthcare-providing institutions throughout the country and play a vital role in the supply chain of pharmaceutical products to customers who are both public and private healthcare providers. Some pharmaceutical wholesalers distribute medical supplies throughout South Africa, and similar to any other business, they need to remain competitive. They employ typical strategic competitive thrusts such as customer service and satisfaction to compete actively in the health market (Antonie et al., 2018). Pharmaceutical wholesalers and its customers operate in a very regulated and competitive market where high quality services are expected, making the interaction and service received from the wholesaler all the more critical (Bangalee \& Suleman, 2015:522:). The quality of service received from the wholesaler strongly affects the service a patient receives down the supply chain, and as such, the wholesaler directly affects the business performance, profitability, customer loyalty, and customer satisfaction of its customers (Mehralian et al., 2016:973).

It is common practice that most of a wholesaler's customers have accounts with several competitive pharmaceutical wholesalers; this is to prevent medicine shortages and also to compare product prices. This business practice makes the principles of being the supplier of choice and customer loyalty all the more difficult to achieve for pharmaceutical wholesalers (Ball, 2011). Customers expect to receive pharmaceutical quality products at a competitive price on time, every time. Any errors from the wholesaler are unacceptable because of the direct impact it can have on the service quality provided by the health service providers to their customers and also on their patients' health and safety. Furthermore, because of the stiff competition in the wholesale pharmaceutical industry and the resultant low price margins of medicine, most pharmacies and doctors are forced to keep smaller quantities of stock on hand and ordering more frequently, thereby making quick deliveries a highly competitive advantage for pharmaceutical wholesalers. 
According to the South African Pharmacy Council (SAPC, 2018), there are 216 pharmaceutical wholesalers registered in South Africa. Pharmaceutical wholesalers are in intense competition with each other, trying to grow their market share by taking business from their rivals, thereby making service satisfaction of customers critical for pharmaceutical wholesalers (Mehralian et al., 2016:973). Figure 1 shows how fragmented and complex the pharmaceutical supply chain is and shows where the pharmaceutical wholesaler and its customers fit in the supply chain of pharmaceutical products.

\section{Figure 1: The South African Pharmaceutical Supply Chain}

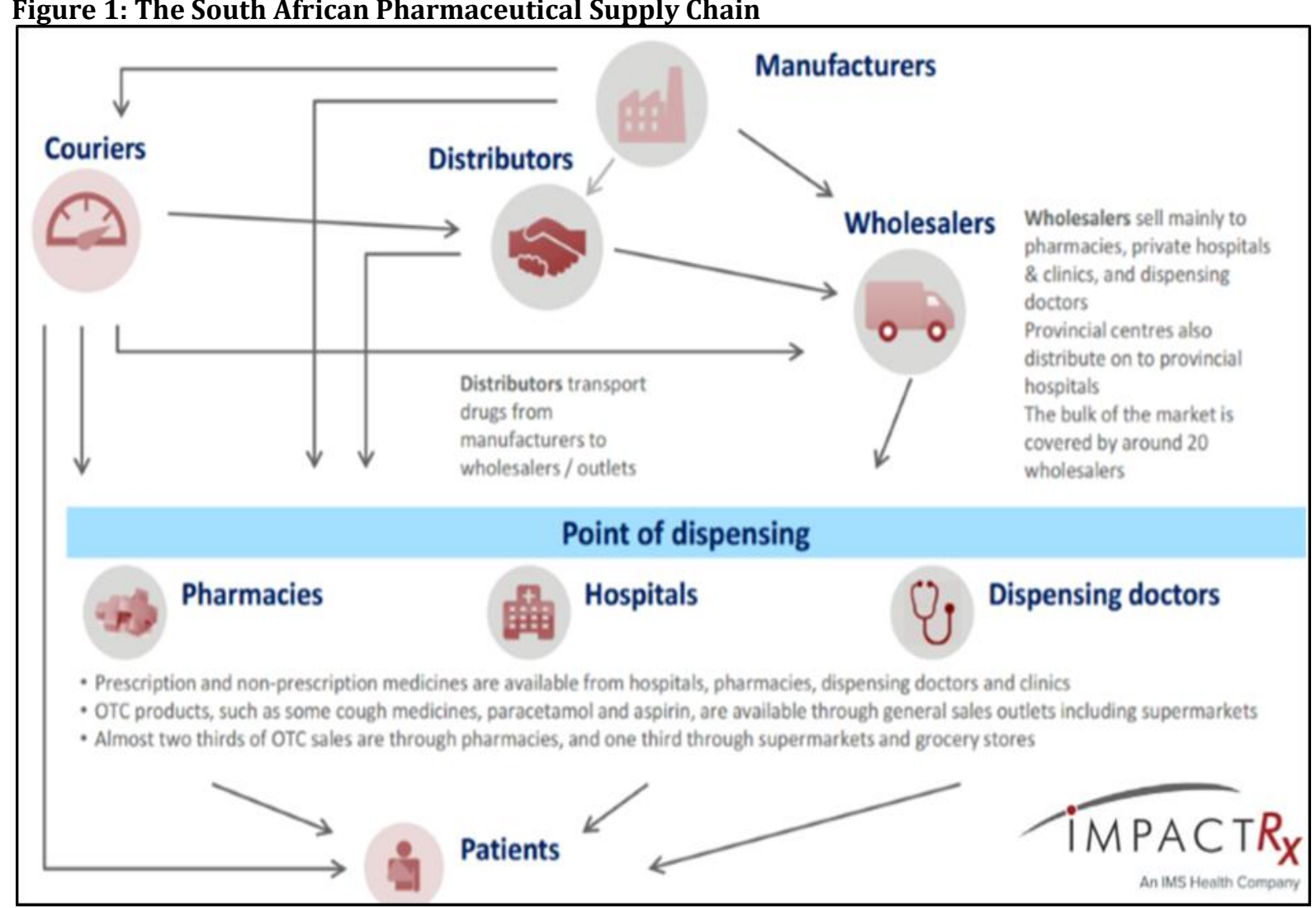

Source: Impact Rx (2016)

According to the Helen Suzman Foundation's report on the supply of pharmaceuticals in South Africa, the top 15 pharmaceutical wholesalers in South Africa account for over $95 \%$ of wholesale turnover (Antonie et al., 2018). These top pharmaceutical wholesalers all focus on service quality as competitive thrust, more specifically promoting the service qualities of availability of a wide range of products, competitive prices, quick and free deliveries, professional and high-quality service, simple invoicing, strong financial relationships, and overall good customer relationships.

Importance of the Study: The study is important for the wholesale industry because customer service is a vital competitive tool in the pharmaceutical wholesale industry. This is more so than in most other industries because the pharmaceutical industry is regulated by a single exit price legislation; this means that the price of pharmaceutical products are standardised and none of the marketing price theories can be used as a competitive tool. Furthermore, products are also standardised, and no product differentiation strategies can be used to compete in the market. Furthermore, most customers hold an account with more than one wholesaler; this means that no switching costs exist to deter customers from switching their pharmaceutical supplier of choice. Probably the most effective competitive strategy a pharmaceutical wholesaler can implement is to deliver excellent customer service. However, to date, no specific customer service managing model could be located that managers of pharmaceutical wholesale organisations could use to measure and manage their service levels. This is the contribution of this study; it presents a developed and tested model to measure and manage customer service of pharmaceutical wholesalers. 
Problem Statement: Pharmaceutical wholesalers compete with each other by providing identical pharmaceutical products and similar services mainly, to private healthcare institutions. These institutions are typically independent and retail-chain pharmacies, doctors, other wholesalers, hospitals, clinics, veterinary facilities, health shops, homeopaths and export customers. To add insult to injury, competitive price regulations of medicine in South Africa imply a single exit price, and as a result, the pharmaceutical wholesalers can no longer compete or use lower prices as a strategic business advantage. The single exit price on medicine makes it almost impossible for customers to differentiate pharmaceutical wholesalers on the cost of (identical) products. As a result, customers have moved their focus to the overall quality of service they receive from pharmaceutical.

Wholesalers (for example, delivery times, ordering errors and consistency) and how well the wholesalers fulfil their service expectations (Ramamoorthy et al., 2018:834). This change in customer focus now forces the pharmaceutical wholesalers to shift their core focus from buying in bulk and getting better deals to promote products at lower prices, towards an overall high-quality service strategy whereby they can differentiate themselves from other pharmaceutical wholesalers. As such, service quality therefore, also has a significant impact on the financial performance of the pharmaceutical wholesaler (Niaz et al., 2009:26) and its long-term profitability. Wholesalers should therefore actively manage their service levels, and a proper point of departure is to measure their service levels. As a result, a study is not only needed to determine the current perceived service quality of pharmaceutical wholesalers but also to develop a model whereby the service quality can be effectively measured to facilitate managerial intervention where needed. This study then aims to develop a model that managers can use to measure the pharmaceutical wholesaler service quality they deliver to their customers so that they can manage towards providing a higher quality of service and also meet customers' expectations.

Objectives: The primary objective of this study is to develop a model to measure the service quality at a pharmaceutical wholesaler. The secondary objectives are to determine the perceived and expected levels of customer service the retail customers receive from the pharmaceutical wholesaler and measure the difference (gap) between them; identify underlying factors that influence the quality of service provided by a pharmaceutical wholesaler, and to formulate managerial interventions to improve service levels to customers. These objectives are serviced based on the SERVQUAL model of customer service (Parasuraman et al., 1985:41; 1988:14; Zeithaml et al., 1990:67) as successfully adapted and applied in health industry studies by various researchers (Niaz et al., 2009:26; Bisschoff \& Kadé, 2010; Ramamoorthy et al., 2018:841; Appalayya \& Paul, 2018:261).

\section{South African Pharmaceutical Wholesale Context}

Features of South African Pharmaceutical Markets: The South African pharmaceutical sector has faced many regulatory changes since the first democratic election and governmental change in 1994, especially about the price control of medicine. Bangalee and Suleman (2015:526), in support of Van den Heever (2003), state that these changes were long overdue and can be attributed mainly to the systemic cost increases in the private healthcare market of South Africa. The pharmaceutical sector is regulated by the Medical and Related Substances Act 101 of 1965 (MARSA) (SA, 1965). This act authorises the South African Health Products Regulatory Agency (SAHPRA, 2018) to set up a framework for the registration of medicines, the classification thereof into schedules, and regulates the purchase and sale of medicines by manufacturers, distributors, wholesalers, pharmacists and persons licensed to dispense medicines. The sales of pharmaceuticals in the private sector are regulated by MARSA (as well as some general regulations); this demarcates a specific supply chain. All entities in the supply chain of pharmaceutical products must be licensed with the Department of Health (DoH). Manufacturers, importers, distributors, retailers and wholesalers are recognised as part of this supply chain. There are three levels where value can be added in the supply chain to pharmaceutical products. They are manufacturer level, where the manufacturer's price is added; the wholesaler/distributor level, where the logistics fees are added; and the retailer level, where the dispensing fee is added.

Manufacturer level: Manufacturers manufacture and set medicine prices in the private sector during their applications for the official approval and registration of a medicine. Prices are subject to ceilings, and the 
periodic adjustment of prices is determined by the Department of Health. Manufacturers, however, can: submit applications to temporarily or permanently reduce the costs of their medicine; and apply for price increases if required to keep the medicine available on the South African market, especially in the case where manufacturers are importers of medicinal ingredients (Antonie et al., 2018).

Wholesaler/Distributor Levels of Distribution: Definitions for "distributor" or "wholesaler", as provided by MARSA, are vague. However, generally, a distributor is defined as "an agent acting on behalf of the manufacturer" and a wholesaler as an entity who "buys in bulk for its own account". Manufacturers make use of either distributors who act as their agents who, therefore, deal with either retailers or wholesalers, or they may use wholesalers who buy in bulk from them and then sell to retailers in smaller quantities. A pharmaceutical wholesaler may only purchase medicine from the "original manufacturer" or the "primary importer" and may only sell to the retail sector as per section 22H of MARSA. On 31 October 2018, the South African Health Products Regulatory Authority (SAHPRA, 2018) had licenced a total of 216 pharmaceutical wholesalers (Antonie et al., 2018).

Retail level: A retail pharmacy is regarded as a business that is allowed to purchase and sell medicine. They may do so by buying directly from a manufacturer, a distributor or a wholesaler. Independent retail pharmacies may prefer to obtain their medicine from wholesalers other than ones integrated with corporate retail pharmacies. They may do so to avoid supporting their competitors. The corporate retailers can buy their medicines from the distributor or wholesaler with whom they are integrated, or from independent wholesalers or distributors, or directly from manufacturers. However, the 15 larger wholesalers account for nearly all pharmaceutical products passing through the South African wholesale distribution chain. The majority of pharmaceutical wholesalers are small regional wholesalers. In the distributor channel, four large distributors dominate the market and account for most pharmaceutical products in this channel.

Licensing and the Supply Chain: It is illegal, as regulated by the Medicines and Related Substances Act (Act 101 of 1965) (SA, 1965), to handle the sale and distribution of any medicines or scheduled substances without a valid licence to do so from the South African Pharmaceutical Council (SAPC, 2018) and SAPHRA. MARSA, along with the General Regulations, governs licences for all entities that form part of the pharmaceutical supply chain.

Pricing Regulations: Single Exit Price (SEP): Historically, consumers often had to pay higher prices on doctors' preferred medicines because incentives were given to the doctors and other healthcare professionals by medicinal manufacturers to prescribe their medicines specifically. However, funding these incentives also increased medicine prices at manufacturer-level. In an attempt to make healthcare more affordable, especially given the country's history of high poverty levels among mostly the previously disadvantaged groups, the South African Government and the Department of Health stepped in. The Medicines and Related Substances Act (Act 101 of 1965) (SA, 1965), which governs the manufacturing, distribution, sales, and marketing of medicines, was amended in 1997 adding sections about the banning of "bonus" stock and the creation of a pricing committee that aimed to enforce a transparent pricing system that includes a Single Exit Price (SEP) for medicines. The single exit price came into effect in 2004, and it is the only price at which a manufacturer may sell medicines to any person (Pretorius, 2011). The SEP consists of a determined price as per manufacturer or importer, the publicly negotiated logistics price (shown separately) between manufacturer and wholesale, and a $15 \%$ value added tax as per government regulations.

\section{Service Quality}

Defining Services: Initially, Zeithaml et al. (1990) defined service broadly as "experiences, performances, and deeds produced or provided by one person or entity for another person or entity". Later, Constantinides (2006:407) stated that a service is "an act or a benefit to the customer, but does not result in the ownership of anything tangible, making it a peculiar characteristic of service compared to goods". He continues to add that it should not be ignored that "products also possess and deliver intangible benefits to customers". Wilson et al. (2012) follow the intangibility debate and state that an important aspect of marketing is that, in essence, customers buy products based on the benefits they provide, and that even the most tangible products also have intangible benefits. This consequently implies that real goods or real services rarely exist, as most offers 
are a combination of tangible and intangible elements. More recently, a service has been defined by Heizer et al. (2017) as "an economic activity that typically produces an intangible product." Furthermore, wholesalers and distributors are entitled to the negotiated logistics fee for their services and pharmacists may add an "appropriate" dispensing fee for their services regarding the regulations.

These definitions and many more, all indicate towards the difficulty to evaluate services because of its intangibility. Furthermore, the customer's experience of a service received is subjective and depends on direct or indirect contact with the service provider. The customer experience on a specific service encounter varies from person to person because it is influenced by customer views, interactions, and lifestyle behaviours; even the mood of the customer on the specific moment when the service is delivered may alter the service experience (Meyer \& Schwager, 2007:116). It is for these reasons that failure or success of a service provided can be determined by certain variables that have an impact on the interaction, cultivation, and attraction between the service provider and its customers. In support, the American Institute for Quality (ASQ) (2019) defines quality as "The totality of features and characteristics of a product or service that bears on its ability to satisfy stated or implied needs".

Characteristics of Services: Services differ from tangible products because of several unique service characteristics that differentiate them from products. Wirtz and Bateson (1999:55) mention that the most important differentiating characteristics are that:

- a service cannot be stored and consumed later (intangibility)

- a service is dependent on the time of delivery (perishability)

- a service is dependent on the place of delivery (locality)

- the customer plays a fundamental role and is part of the service delivery process (inseparability)

- the customer's perception of service quality is influenced by his own experiences and perceived quality expectations, nor is every service delivery encounter exactly duplicated (heterogeneity and variability).

Here many service specialists (such as Putit et al., 2011; McDonald et al., 2011; Fahy and Jobber, 2012; Heizer et al., 2017) agree that service characteristics have important implications for marketing and management decision-makers in their quest to deliver quality service and use service quality as a competitive tool.

Managing Service Quality: Quality is defined differently, and the definition thereof largely depends on different products, services and industries (Wicks \& Roethlein, 2009:85). Own orientations and perspectives also influence the definitions of quality. The International Organization for Standards (ISO) (2018) defines quality as "the degree to which a set of inherent characteristics fulfils the requirement". This is one of the most accepted and used quality definitions. Another more practical view, held by Heizer et al. (2017), state that quality can have significant implications for organisations regarding their company reputation, product and service liability and also have global consequences. Managing quality (and service quality) is a worthy competitive thrust, and developing and implementing practical and applicable service quality strategies can differentiate an organisation. This is especially true in the case (such as the pharmaceutical wholesale industry) where other competitive tools (such as price, product or quality of merchandise) are not at the disposal of managers to use. In such cases, delivering high-quality service is a key to sustainable competitive advantage and will result in satisfied customers. As customers continue to upgrade their service expectations, service providers are forced to better their levels of courtesy and assistance. Consequently, Mehralian et al. (2016:981) state that it is of high importance for companies to differentiate themselves and continuously upgrade the quality of their services to compete in a modern competitive environment.

According to Bisschoff and Hill (2018:1449), service quality has a significant impact on the customers' repurchase intentions, their loyalty and also the recommendations they make. This is vital for pharmaceutical wholesalers to retain their customers and to create favourable behavioural intentions (Putit et al., 2011:147) because these factors positively influence an organisation's future revenue and profits. This is especially relevant in the pharmaceutical wholesale industry, where customers deal with more than one supplier. Here, Mehralian et al. (2016:979) point out that service quality management is the key to remain the supplier of choice in the highly competitive health market. Service quality also positively affects patient satisfaction, 
which, in turn, increases customer loyalty and customers' purchase intentions (Bisschoff \& Hill, 2018:1501). However, most research on service quality in the healthcare sector focuses on the patient service experience, while the pharmaceutical supply chain as an integral part of healthcare services is rarely studied (Mehralian et al., 2016:981). The services that patients receive are strongly influenced by the quality of service received from the pharmaceutical wholesaler as part of the supply chain. This supply chain process is complex, and although the pharmaceutical wholesaler sells tangible goods, the service rendered is of the utmost importance not only for the competitiveness of the pharmaceutical wholesaler but also for the safety of patients. Mehralian et al. (2016:977), state that even minor errors at a pharmaceutical wholesaler are unacceptable due to the many challenges and the sensitivity of the pharmaceutical supply chain that can have a direct impact on the health and safety of patients.

\section{Research Methodology}

Questionnaire Design: Van Heerden (2010) states that the SERVQUAL model has been used numerous times to measure service quality in different industries; Clapton (2013) affirms that the SERVQUAL model has been used in various health institutions. A study conducted by Mehralian et al. (2016:975) developed a service quality measurement instrument for pharmaceutical retailers and pharmaceutical distributors. Based on this research and SERVQUAL principles, the questionnaire was adapted for use to measure the service quality of a pharmaceutical wholesaler in South Africa. The validity of the original SERVQUAL questionnaire has repeatedly been confirmed by several researchers in the medical industry (Bisschoff and Kade, 2010; Carrillat et al., 2007:475; and Adebisi and Lawal, 2017:4). Although the original SERVQUAL model's strength lies in the fact that it was designed not to be industry specific, these authors showed that it is not only a valid tool for the medical industry but also suitable to be adapted for more specific use (for example, for the use by pharmaceutical wholesalers in South Africa). Although this might pose a threat to the validity of the questionnaire, the validity of the modified questionnaire and the reliability of the data were confirmed statistically in this study.

Regarding validity and reliability, the questionnaire was:

- Firstly, subjected to face- and content validity by presenting it to a group of experts in the field of the pharmaceutical supply chain. This included pharmacists, quality assurance pharmacists, pharmaceutical wholesale managers, sales and marketing managers, logistics managers, financial managers and supply chain managers as well as personnel knowledgeable in the field of customer service to evaluate and scrutinise both the question formulations and the layout of the modified service quality measurement scale. They were also instructed to suggest any missing service quality concepts they deem essential in such a service quality study. These suggestions and changes were made to the questionnaire to finalise it.

- Secondly, the questions measuring each of the five service dimensions (Reliability: questions 1-9; Tangibility: questions 10-15; Assurance: questions 16-21; Empathy: questions 22-26; Responsiveness: questions 27-29) were subjected to factor analysis to confirm that these criteria indeed do measure the specific dimension.

- Thirdly, the reliability coefficient Cronbach alpha was used to calculate the reliability of the data.

The questionnaire was designed in Google Forms in such a way that all relevant questions had to be answered, ensuring completeness. Confidentiality was secured for each participant. The questionnaire consists of three sections. Section A captures the classifying variables such as the customer's first choice of pharmaceutical wholesaler, customer referrals of this pharmaceutical wholesaler to other healthcare professionals, and customers type (doctor, hospital or pharmacy). A seven-point Likert scale ranging from 1 (strongly disagree) to 7 (strongly agree) was used to capture the service quality perceptions of the respondents. 
Study Population: The study population consists of all customers of a leading pharmaceutical wholesaler and is geographically located all over South Africa. The company's customer list comprises independent and retail pharmacies, doctors, hospitals, clinics and veterinarians; all of them formed part of the study population. This study specifically selected this target population because the wholesales one of the three largest pharmaceutical wholesalers, it specifically employs customer service as a competitive strategy, and management was willing to share their database with the researchers. No sample was drawn. All the customers on the address list received the adapted questionnaire via email. To ensure that sufficient data were collected, a call centre was used to remind the customers to complete the questionnaires online. The call centre had to follow-up frequently throughout the two weeks of questionnaire distribution to ensure that all willing customers received and completed the questionnaire.

Data Collection: Data collection followed four steps. They were:

Step 1: Permission - The study was approved during a managerial meeting by the operational manager of the pharmaceutical wholesaler, as well as the wholesaler's responsible pharmacist.

Step 2: Awareness - A formal letter per email was sent from the pharmaceutical wholesaler, and the call centre helped to sensitise and explain the purpose of the study.

Step 3: Distribution - The formal letter that was sent by the pharmaceutical wholesaler had a link to Google Forms that opened the questionnaire to all customers of the pharmaceutical wholesaler. The questionnaires were distributed on a specific date, and the deadline was communicated to all personnel and customers to maximise the response rate quantity of completed questionnaires.

Step 4: Collection - The call centre of the pharmaceutical wholesaler assisted in the distribution of the questionnaires and making follow-up reminder calls over a two-week data-collection period. After the agreed time frame, the questionnaires and data were collected from the Google Forms platform and analysed.

Over the two-week data-collection period, a total of 4468 questionnaires were distributed via email and a total of 385 were received back. This signifies a response rate of $8.6 \%$. The response rate was adequate as the Kaiser, Meyer and Olkin value of 0.96 exceeded the required adequacy value of 0.70 with ease (Field, 2009:668) (see also Table 4).

Statistical Analysis and Decision Criteria: The data was captured on Microsoft Excel and imported into the $25^{\text {th }}$ version of the Statistical Package for Social Science (IBM SPSS, 2018) where data analysis was performed. Microsoft Excel was used to determine the effect size or practical significance on the information received. The specialised statistical software was used for the more advanced statistics, which included the reliability of the data, as well as exploratory factor analysis to identify underlying factors within the quality of service dimensions. The Bartlett test of sphericity and the Kaiser, Meyer and Olkin measure of sampling adequacy measure were also calculated to determine if the data was suitable to be subjected to factor analysis. The data and their respective decision-criteria were analysed using several quantitative statistical techniques, as shown in the statistical analysis decision tree in Figure 2 (originally developed by Naidoo, 2011). 
Figure 2: Data Analyses Decision Tree

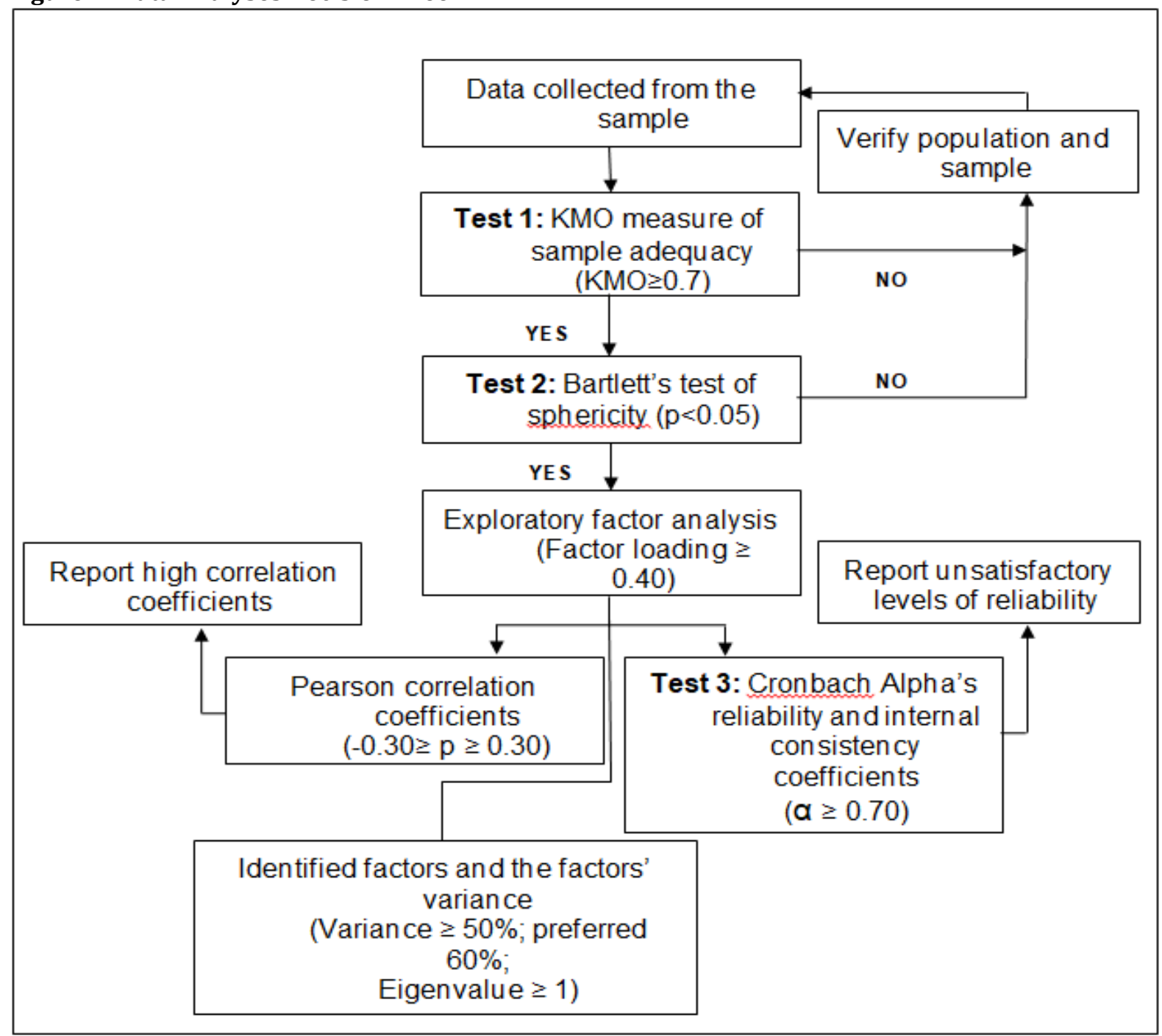

Source: Adapted from Arbuckle (2012), Naidoo (2011:19), and Field (2009)

* This study did not employ Pearson correlations

Ethical Considerations: This study applied the following ethical principles:

- Participation in the survey was voluntary

- Personal data of the customers that participated voluntarily was processed lawfully and fairly and used only for the study

- Personal responses from customers were not ascribed to any individual

- The questionnaire did not contain the names or any other personal information of customers, and the anonymity of customers was maintained throughout the study

- The interpretation of the survey finding was upheld with independent objectivity.

This study was evaluated for compliance with the ethical standards, practices and requirements of the NorthWest University's Ethics Committee (Faculty of Economic and Management Sciences). The committee approved the study and classified it as a low-risk study; a study-specific ethics number (NWU-00271-18-A4) was issued. 


\section{Results}

Demographic Analysis: Three customer categories participated, namely pharmacies, doctors and other customers (represented by wholesalers, hospitals, clinics, veterinary facilities, health shops, homeopaths and export customers). Some $39.5 \%$ of the respondents were pharmacies, $38.2 \%$ were doctors, and the other category accounted for $22.3 \%$. Regarding delivery methods preferred, customers receiving inventory delivered by the wholesaler's delivery vehicles account for $75.6 \%$, whereas customers who are receiving courier deliveries account for $24.4 \%$. Regarding an overall service quality measure, customers who are satisfied with the overall service from the pharmaceutical wholesaler amount to $97.7 \%$, in comparison with $2.3 \%$ who said they were not satisfied. This represents an excellent satisfaction percentage, and the wholesaler should strive to maintain these service levels.

SERVQUAL GAP 5 Analysis: The data received about the different dimensions of service delivery that were addressed by the questionnaire will now be analysed and discussed. The level of actual or perceived service delivery is compared with the expected level of service delivery and the gap between the two levels was determined. The results are presented in Table 1. The criteria in the tables represent the summary index values per statement. The average expected service and perceived service per statement are followed in the next column by the difference between them, while the overall averages appear in the last row of Table 1 .

Table 1: SERVQUAL GAP 5 Results

\begin{tabular}{|c|c|c|c|c|c|}
\hline \multirow{2}{*}{ Dimension } & \multirow{2}{*}{ Statement } & \multicolumn{2}{|c|}{ Average scores } & \multirow[t]{2}{*}{ E-p } & \multirow{2}{*}{$\begin{array}{l}\text { Average for } \\
\text { dimension }\end{array}$} \\
\hline & & $\mathbf{E}$ & $\mathbf{P}$ & & \\
\hline \multirow{6}{*}{ Assurance } & 15. Order placing are accurate & 6,252 & 5,839 & 0,413 & \multirow{6}{*}{0,484} \\
\hline & 16. Stock delivered on time & 6,488 & 5,919 & 0,569 & \\
\hline & 17. Deliveries incorporate specific business needs & 6,294 & 5,938 & 0,356 & \\
\hline & 18. Call centre agents are professional & 6,384 & 5,956 & 0,429 & \\
\hline & 19. Ability to resolve queries & 6,283 & 5,608 & 0,675 & \\
\hline & 20. aims to provide excellent service & 6,439 & 5,977 & 0,462 & \\
\hline \multirow{5}{*}{ Empathy } & $\begin{array}{l}\text { 1. Interest in solving any product related } \\
\text { problems }\end{array}$ & 5,919 & 5,327 & 0,592 & \multirow{5}{*}{0,437} \\
\hline & 21. Sincere interest in solving problems & 6,312 & 5,743 & 0,569 & \\
\hline & 22. Call centre is easy to reach & 6,343 & 5,951 & 0,392 & \\
\hline & 23. Payment methods are convenient & 6,395 & 6,216 & 0,179 & \\
\hline & 24. Fulfil specific business requirements & 6,325 & 5,873 & 0,452 & \\
\hline \multirow{4}{*}{$\begin{array}{l}\text { Responsive- } \\
\text { ness }\end{array}$} & 25. Responds effectively to account enquiries & 6,351 & 5,966 & 0,384 & \multirow{4}{*}{0,544} \\
\hline & 26. Responds effectively to complaints & 6,304 & 5,740 & 0,564 & \\
\hline & 27. Inform on when order will be delivered & 6,195 & 5,574 & 0,621 & \\
\hline & 28. Delivers in time and in full & 6,408 & 5,800 & 0,608 & \\
\hline \multirow{6}{*}{ Reliability } & 2. Deliveries contain correct products & 6,509 & 6,195 & 0,314 & \multirow{6}{*}{0,483} \\
\hline & 3. Deliveries contain correct quantities & 6,447 & 6,088 & 0,358 & \\
\hline & 4. Competitive pricing on non-SEP products & 6,177 & 5,644 & 0,532 & \\
\hline & 5. Promotions communicated effectively & 6,135 & 5,771 & 0,364 & \\
\hline & 6. Relevant promotions & 5,953 & 5,525 & 0,429 & \\
\hline & 7. Stock all relevant items required in business & 6,075 & 5,174 & 0,901 & \\
\hline \multirow{3}{*}{ Tangibility } & 8. Packaging material of good quality & 6,470 & 6,153 & 0,317 & \multirow{3}{*}{0,281} \\
\hline & 9. Modern online website & 6,042 & 5,486 & 0,556 & \\
\hline & 10. Marketing materials visually appealing & 6,481 & 6,325 & 0,156 & \\
\hline
\end{tabular}




\begin{tabular}{lllll}
\hline & 11. Vehicles well branded & 6,145 & 6,026 & 0,119 \\
& 12. Drivers act professionally & 6,353 & 6,029 & 0,325 \\
& 13. Drivers are professional in appearance & 6,244 & 5,860 & 0,384 \\
14. Cold chain is maintained for fridge parcels & 6,517 & 6,405 & 0,112 \\
TOTAL & & $\mathbf{6 , 2 9 4}$ & $\mathbf{5 , 8 6 1}$ & $\mathbf{0 , 4 3 3}$ \\
\hline
\end{tabular}

The analysis shows that the customers' expected service from the wholesaler was not met. The table shows that there is a positive gap between the expected services and perceived service levels. This means that the services rendered to customers did not meet nor exceed the customers' service expectations. All five dimensions have positive gaps. The overall gap of the mean scores for the 28 statements is 0.433 (6.294 (expectations) less 5.861 (perceptions)). Regarding the five dimensions, the customer expectation for the assurance dimension is the highest with an average of 6.357 , followed closely by the tangible and responsiveness dimensions with averages of 6.322 and 6.314. The dimension with the lowest average customer expectation is that of reliability, with an average of 6.219. The most significant gap between customer expectations and perceptions is that of the responsiveness dimension with a difference of 0.544 .

Significance of the Gaps: The effect size, or practical significance (d), was used as a measure to determine whether significant differences exist between the perceptions and the expectation of the customers. The effect size (d-value) ranges between 0 and 1 . A d-value of 0.8 and higher implies that there is a large practical significance. Values between 0.5 and 0.8 suggest medium practical significance, where a d-value of more than 0.2 but less than 0.5 signifies a small or moderate significance (Ellis, 2010). For this study, d-values of 0.2 and above (thus indicating low or high levels of practical significance) are considered significant differences between the perceptions and the expectation of the customers. The results of the effect sizes of each of the five service dimensions appear in Table 2.

Table 2: Effect Size per Dimension

\begin{tabular}{llllll}
\hline Item & $\mathbf{E}$ & $\mathbf{P}$ & $\begin{array}{l}\text { Difference in } \\
\text { average }\end{array}$ & $\begin{array}{l}\text { Standard } \\
\text { deviation }\end{array}$ & $\begin{array}{l}\text { Effect } \\
\text { size }\end{array}$ \\
\hline Assurance & 6,357 & 5,873 & 0,484 & 1,463 & $\mathbf{0 , 3 3 1}$ \\
Empathy & 6,259 & 5,822 & 0,437 & 1,440 & $\mathbf{0 , 3 0 3}$ \\
Responsiveness & 6,314 & 5,770 & 0,544 & 1,535 & $\mathbf{0 , 3 5 5}$ \\
Reliability & 6,216 & 5,733 & 0,483 & 1,425 & $\mathbf{0 , 3 3 9}$ \\
Tangible & 6,322 & 6,040 & 0,281 & 1,359 & $\mathbf{0 , 2 0 7}$ \\
\hline
\end{tabular}

The practical significance between the perceptions and expectations in all five dimensions of service quality are moderate to low with d-values between 0.2 and 0.5 . In practice, this means that there are no significant discrepancies in service quality levels between what the customers expect and what they received.

Reliability of Dimensions: The Cronbach alpha $(\alpha)$ coefficient was calculated to statistically determine the reliability of the data in all five the service quality dimensions. Cronbach's alpha determines the internal consistency or average correlation of items in a survey instrument to gauge its reliability (Bryman \& Bell, 2014). Typically, an adequate sample and sufficiently low sphericity are data properties that are required to extract meaningful factors from the data successfully. This study employed the Kaiser-Meyer-Olkin test to determine the suitability of the data for factor analysis. An acceptable level of reliability is usually implied by a result of 0.7 and above, although most researchers accept an alpha coefficient of 0.7 as acceptable (Field, 2009:668). The minimum alpha coefficient for this research was therefore set at $\alpha \geq 0.70$. Table 3 below shows the reliability coefficients for all the antecedents of service quality. All the antecedents have returned very satisfactory reliability coefficients of more than 0.8 . This exceeds the minimum coefficient of 0.7 by far and shows excellent reliability and internal consistency of data about each dimension. 
Table 3: Reliability Coefficient

\begin{tabular}{ll}
\hline Dimensions & Cronbach Alpha $(\boldsymbol{\alpha})$ \\
\hline Reliability & 0,884 \\
Tangibility & 0,894 \\
Assurance & 0,920 \\
Empathy & 0,897 \\
Responsiveness & 0,890 \\
Total data set & $\mathbf{0 , 8 9 6}$ \\
\hline
\end{tabular}

Exploratory Factor Analysis: Successful exploratory factor analysis requires data that is suitable for multivariate analysis. Furthermore, Bartlett's test of sphericity was used to determine the sphericity within the data. Low sphericity (below 0.05$)$ and high sample adequacy $(\geq 0.70)$ are needed to determine whether the data is suitable to be used for exploratory factor analysis (Williams et al., 2010:10). The results appear in Table 4.

Table 4: Kaiser-Meyer-0lkin Measure and Bartlett's Test

\begin{tabular}{lll}
\hline Kaiser-Meyer-Olkin Measure of Sampling Adequacy & $\mathbf{0 , 9 6 3}$ \\
\hline Bartlett's test of sphericity & Approx. chi-square & 10133,241 \\
& Df & 378 \\
& Sig. & $\mathbf{0 , 0 0 0}$ \\
\hline
\end{tabular}

The Kaiser-Meyer-Olkin measure displays a value of 0.963 , indicating that the sample is adequate. The Bartlett's test of sphericity also returned a favourable value less than the required value of 0.05 . Three factors were identified with exploratory factor analysis using an orthogonal varimax rotation. According to Beavers et al. (2013:10), rotational techniques such as varimax serve to create a more interpretable solution than Principal component analysis, because it identifies factors and the communalities without altering the structural relationships, while Field (2009:746) points out that a varimax rotation is particularly suitable for exploratory studies (like this one) because it aims to maximise the variance per factor explained. Field (2009:667) also stated that factor loadings of 0.40 and above are considered to be significant and are used in the analysis. Table 5 below indicates that all 28 of the statements loaded onto three factors; all had factor loadings of 0.40 or higher. The table also shows the variance explained and reliability of the factors.

Table 5: Rotated Factor Structure

\begin{tabular}{llll}
\hline NR & Statement & Factors & \\
& $\mathbf{1}$ & $\mathbf{2}$ & \\
\hline A5(P) & 19. Ability to resolve queries & 0,788 & \\
E2(P) & 21. Sincere interest in solving problems & 0,786 & \\
E1(P) & 1. Interest in solving any product related problems & 0,738 & \\
A4(P) & 18. Call centre agents are professional & 0,713 & \\
A6(P) & 20. Aims to provide excellent service & 0,694 & \\
E5(P) & 24. Fulfil specific business requirements & 0,689 & \\
R2(P) & 26. Responds effectively to complaints & 0,677 & \\
E3(P) & 22. The call centre is easy to reach & 0,670 & \\
R1(P) & 25. Responds effectively to account enquiries & 0,659 & \\
R3(P) & 27. Inform on when the order will be delivered & 0,653 & \\
A1(P) & 15. Order placing is accurate & 0,613 & \\
RL6(P) & 7. Stock all relevant items required in business & 0,536 & \\
T5(P) & 12. Drivers act professionally & & 0,739 \\
A2(P) & 16. Stock delivered on time & & 0,686 \\
R4(P) & 28. Delivers on time and in full & 0,678 \\
\hline
\end{tabular}




\begin{tabular}{llll}
\hline RL2(P) & 2. Deliveries contain correct quantities & 0,667 \\
T4(P) & 11. Vehicles well branded & 0,666 \\
RL1(P) & 3. Deliveries contain correct products & 0,661 \\
T6(P) & 13. Drivers are professional in appearance & 0,661 \\
A3(P) & 17. Deliveries incorporate specific business needs & 0,634 \\
T7(P) & 14. The cold chain is maintained for fridge parcels & 0,603 \\
T1(P) & 8. Packaging material is of a good quality & 0,577 \\
E4(P) & 23. Payment methods are convenient & 0,536 & \\
RL5(P) & 6. Relevant promotions & & 0,712 \\
RL4(P) & 5. Promotions communicated effectively & & 0,653 \\
T2(P) & 9. Modern online website & & 0,631 \\
RL3(P) & 4. Competitive pricing on non-SEP products & & 0,618 \\
T3(P) & 10. Marketing materials visually appealing & & 0,598 \\
Percentage of variance explained & $\mathbf{2 8 , 3 1 \%}$ & $\mathbf{2 3 , 1 1 \%}$ & $\mathbf{1 6 , 2 3 \%}$ \\
Cumulative percentage of variance & $\mathbf{2 8 , 3 1 \%}$ & $\mathbf{5 1 , 4 3 \%}$ & $\mathbf{6 7 , 6 6 \%}$ \\
Reliability (Cronbach alpha) & $\mathbf{0 , 9 5 9}$ & $\mathbf{0 , 9 4 1}$ & $\mathbf{0 , 8 6 6}$ \\
\hline
\end{tabular}

It is noteworthy from the table that a satisfactory cumulative variance is explained by the three factors (67.66\%), which exceed the desired variance explained of $60 \%$. Regarding the reliability coefficients for all three factors, it is evident that all three of them returned very satisfactory reliability coefficients, exceeding the required coefficient of 0.7 with ease. Factors 1 and 2 have reliability coefficients higher than 0.90 , whereas Factor 3 has an alpha coefficient that is higher than 0.8 .

Factor 1: Positive Employee Actions: A total of 12 statements, namely statements number 19, 21, 1, 18, 20 , $24,26,22,25,27,15$ and 7 loaded onto factor 1 . All the statements under factor 1 deal with positive actions undertaken by the employees to prevent complaints and ensure a good service to customers. The factor is therefore labelled as Positive employee actions. Statements 1, 18, 19, and 21 all have factor loadings more than 0.70, suggesting that these statements are regarded as significant by the customers of the pharmaceutical wholesaler the factor explains a variance of $28.31 \%$. Woods et al. (2012:201) conducted a study to examine the relations of organisational commitment and demographic factors with objectively measured absence frequency. The results of this study are supported by Woods et al. (2012:202) who stated that organisations could benefit from employees with high organisational commitment and well-being because their positive actions can increase levels of customer satisfaction, generate higher profit, increase productivity, and lower turnover rates. Studies have also shown that organisational commitment and positive employee actions are closely connected to job satisfaction, and that satisfied employees deliver better service overall (Harrison et al., 2006:307).

Factor 2: Business Process Management: Statements 12, 16, 28, 2, 11, 3, 13, 17, 14, 8 and 23 all loaded onto factor 2 . Only statement 12 has a factor loading above 0.70 , but the rest of the statements are well above the cut-off factor loading of 0.40 . All the statements relate to business process controls that management set in place to ensure good service quality. The factor identifies business process management; the factor is labelled as such. The factor explains a variance of $23.11 \%$. Ziemba and Obłąk (2013:15) studied the critical success factors for successful enterprise resource planning (ERP) systems implementation in public administration. This identified factor is in support of the results achieved in a study by Ziemba and Obłąk (2013:16) as they argue that organisations are constantly seeking ways to increase customer satisfaction, increase efficiency, improve product quality, and reduce costs. Organisations have realised that it lies in the performance of their processes. Hsu et al. (2015:927) examined the relative importance that ERP system quality has on the service quality rendered to customers. Their findings are similar to that of Ziemba and Obłąk (2013:12) who concluded that service quality was found to interact with information quality and system quality significantly. 
Factor 3: Marketing Channels: Five statements, namely: 6, 5, 9, 4 and 10 loaded onto factor 3. These statements describe the marketing channels the pharmaceutical wholesaler use to connect with customers. The factor is therefore labelled as marketing channels because it shows the effect that organisational marketing channels have on the customers' service perceptions of the pharmaceutical wholesaler. Statement 6 reflects a factor loading above 0.70, suggesting that the customers regard targeted promotions as very important. The factor has a variance of $16.23 \%$. The findings are supported by Aghazadeh (2015:127) in a study on the development of a comprehensive model for integrated marketing strategy, which argues that marketing strategies and channels used can be a competitive advantage as it can attract customers, create value for customers, satisfy customers, and encourage customers to return.

A Model to Measure Customer Service at a Pharmaceutical Wholesaler: The model to measure customer service in this study was developed in three stages. In the first stage, the model employed a sound theoretical basis to identify the relevant customer service measuring criteria to the wholesale pharmaceutical industry. These criteria were classified into the five customer service antecedents, namely tangibility, responsiveness, assurance, reliability and empathy as per the SERVQUAL model in the second stage. The third and final stage of the model construction then subjected the measuring criteria to exploratory factor analysis to identify the latent variables of customer service at a pharmaceutical wholesaler. Three factors were identified. The model is shown in Figure 3.

\section{Figure 3: An Integrated Model to Measure Customer Service at a Pharmaceutical Wholesaler}

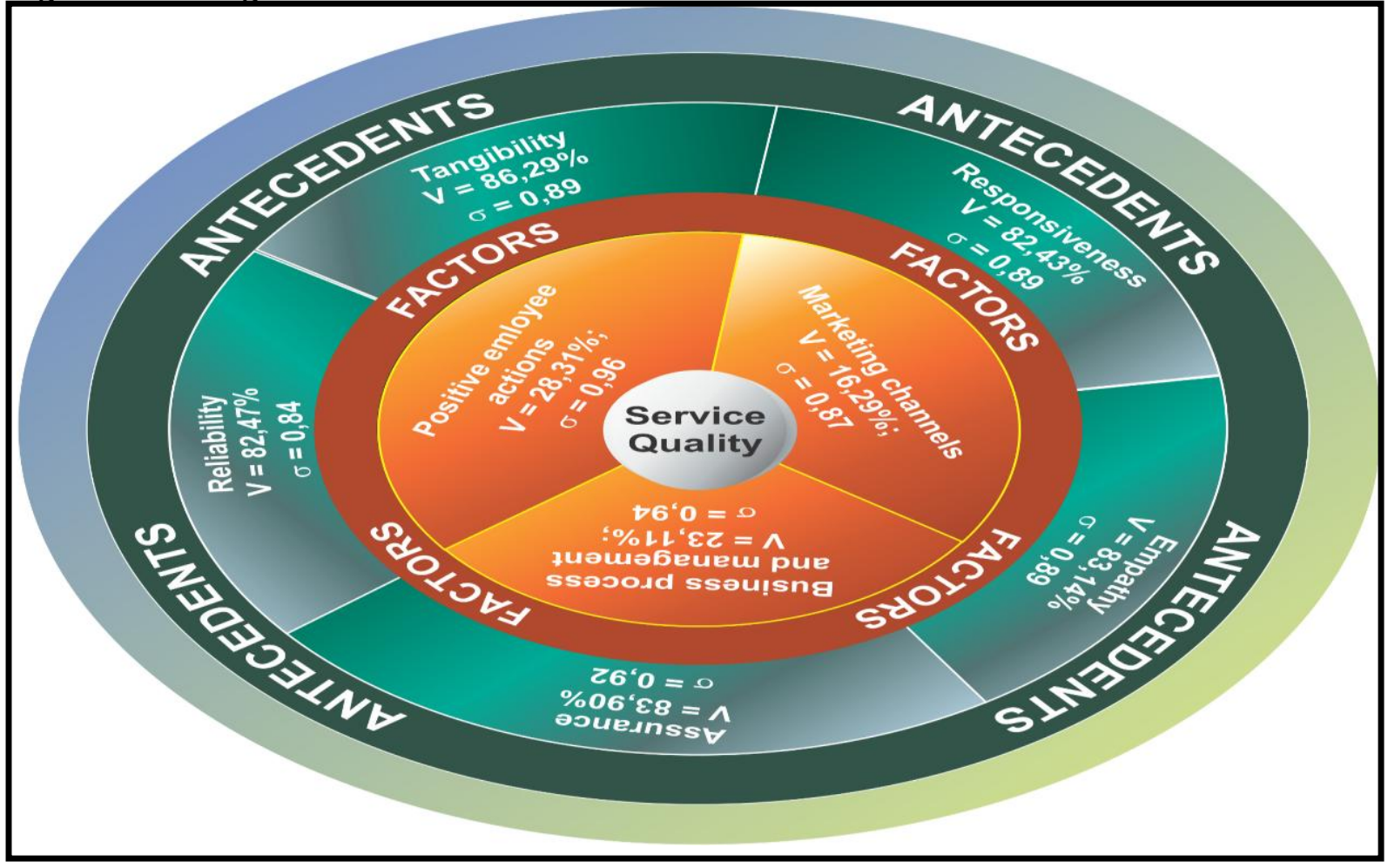

The model shows that all five of the customer service antecedents are highly reliable; they have Cronbach alpha coefficients of more than 0.80 . Furthermore, these antecedents explain high percentages of variance each (exceeding $80 \%$ variance explained in all the cases). In practice, this means that each antecedent does measure the service quality antecedent well. Regarding the factors (or latent variables), all three also have high Cronbach alpha coefficients, and they explain a satisfactorily cumulative variance of almost $68 \%$. This model is a practical tool for use by managers if they want to measure the customer service of a pharmaceutical wholesaler. The model could be highly productive if these managers apply the findings of their measurements to improve poor service areas while also trying to maintain excellent service areas. However, without measuring, there can be no accurate managerial intervention to enhance the quality of service. Herewith lies the benefit of this study; it provides a reliable tool to measure customer service in 
practice that can be used to improve the competitive stance of a wholesaler in a highly competitive environment where no product differentiation exists.

\section{Conclusion and Recommendations}

Three sets of conclusions are drawn based on the findings of this study. This includes conclusions from the literature review, the empirical results and the model to measure service quality.

The literature study concludes that:

- The South African pharmaceutical wholesale industry is a highly competitive business environment.

- The industry is highly controlled by law, government regulations and formal bodies.

- Competitiveness is seriously influenced by the single exit pricing (SEP) regulation.

- It is standard practice for customers to have more than one wholesaler as a supplier.

- Pharmaceutical wholesalers cannot use price to compete in the market and must find another competitive edge.

- Overall, the South African pharmaceutical wholesalers' industry aims to compete using service quality and strategic thrust.

- No validated South African service quality measurement model could be identified that managers can apply as is.

The empirical results lead to the following conclusions:

- Overall the customers of the wholesalers are happy with the service quality levels they receive.

- There are differences (negative gaps) between all five the service quality antecedents which indicate that although they are happy with the service levels, the customers are expecting an even better service quality experience from their pharmaceutical wholesaler.

- Although these gaps exist, they are not practically significant. However, the fact that there are gaps should not be discarded, and management should attempt to decrease or eliminate these gaps in totality.

- The data collected are statistically reliable and can, therefore, be analysed with confidence.

- Three factors also exist that can be managed to improve service levels, namely Business processes, Marketing Channels and Positive employees.

Regarding the development of the model to measure service quality in the pharmaceutical wholesale industry is can be concluded that:

- The SERVQUAL model successfully served as a basis to develop a measurement model for the pharmaceutical wholesale industry.

- The model could be adapted to service pharmaceutical wholesale measurements specifically.

- The developed model can be applied in practice for managerial applications and interventions.

Finally, it is concluded that the proposed customer service research model provides relevant management information and appears to be successful in determining the quality of service of a pharmaceutical wholesaler.

Recommendations: Based on the conclusions, recommendations are that:

- Managers of pharmaceutical wholesale organisations should take note of the model to measure service quality. It could assist them greatly to determine service quality levels, and then also to be more competitive in a non-price competition business environment.

- Managers should also note that measuring service quality is merely the diagnosis but that managerial interventions based on the measurement results are the key to enhance competitiveness (merely doing the measurement is not good enough).

- Despite the five service dimensions, three additional key service factors have been identified. These should also be managed actively to enhance the customer experience.

- Although the negative gaps between the five service dimensions are not practically significant, it is recommended that managers should seriously consider the gaps because marginal deteriorations might result in practical significant gaps; at that stage, service quality will be compromised. 
- Finally, it is recommended that future researchers who plan to investigate service quality should take note of this research model. The model may, or may not be used as is for their project, but it can provide a cognitive roadmap for innovative thinking and future studies.

Summary: This study set the objective to use and adapt a validated model to measure service quality, and then test the model by applying it in practice. In doing so, developing a tailormade model for the pharmaceutical industry the data were used to test the reliability and validity of the model (using factor analysis) to ensure that it does measure what was intended, namely the service quality of pharmaceutical wholesalers. The developed model is also visually presented for ease of understanding and application. Finally, the article drew conclusions and also presented some recommendations to managers to apply in the pharmaceutical wholesale industry.

\section{References}

Adebisi, O. S. \& Lawal, K. O. (2017). The impact of service quality on customer loyalty: a study of pharmaceutical firms. Nigerian Chapter of Arabian Journal of Business and Management Review, 62(139), 1-5.

Aghazadeh, H. (2015). Strategic marketing management: achieving superior business performance through intelligent marketing strategy. Procedia - Social and Behavioral Sciences, 207, 125-134.

American Institute for Quality (ASQ). (2019). Defining "Quality". San Antonio, CA: ASI.

Antonie, F., Simkins, C., van Dalsen, A., Chetty, K., Collocott, C., Toxopeus, M. \& Doodnath, A. (2018). The Pharma Report: The supply of pharmaceuticals in South Africa. Johannesburg: The Helen Suzman Foundation.

Appalayya, M. \& Paul, J. (2018). Service quality, consumer satisfaction and loyalty in hospitals: thinking for the future. Journal of Retailing and Consumer Services, 40, 261-269.

Arbuckle, J. L. (2012). IBM SPSS Amos 21 user's guide. Seattle, WA: Amos Development Corporation.

Ball, D. (2011). The regulation of mark-ups in the pharmaceutical supply chain. WHO/HAI Project on Medicine Prices and Availability. Review Series on Pharmaceutical Pricing Policies and Interventions, Working Paper, 3. Johannesburg: WHO.

Bangalee, V. \& Suleman, F. (2015). Evaluating the effect of a proposed logistics fee cap on pharmaceuticals in South Africa - a pre and post analysis. BMC Health Services Research, 15(1), 522-533.

Beavers, A. S., Lounsbury, J. W., Richards, J. K., Huck, S. W., Skolits, G. J. \& Esquivel, S. L. (2013). Practical considerations for using exploratory factor analysis in educational research. Practical Assessment, Research \& Evaluation, 18(6), 1-13.

Bisschoff, C. A. \& Hill, H. (2018). Measuring the brand loyalty of farmers in the free state province towards agricultural businesses. Proceedings of the 12 International Business Conference, Turtle Beach, Maurituis, 1448-1465.

Bisschoff, C. A. \& Kade, A. (2010). Customer service of an ophthalmology practice. Paper delivered at the $4^{\text {th }}$ International Business Conference, Livingstone, Zambia, 8-10 Oct.

Bryman, A. \& Bell, E. (2014). Research methodology: Business and management contexts. Cape Town: Oxford University Southern Africa.

Carrillat, F. A., Jaramillo, F. \& Mulki, J. P. (2007). The validity of the SERVQUAL and SERVPERF scales: A metaanalytic view of 17 years of research across five continents. International Journal of Service Industry Management, 18(5), 472-490.

Clapton, J. (2013). Measuring service quality in a private hospital. (Dissertation - MBA). Potchefstroom: North West University.

Constantinides, E. (2006). The marketing mix revisited: towards the $21^{\text {st }}$ century marketing. Journal of Marketing Management, 22(3/4), 407-438.

Ellis, P. D. (2010). The essential guide to effect sizes: Statistical power, meta-analysis, and the interpretation of research results. Pretoria: Cambridge.

Fahy, J. \& Jobber, D. (2012). Foundations of marketing. Maidenhead: McGraw-Hill Education.

Field, A. (2009). Discovering statistics using SPSS. London: Sage.

Harrison, D. A., Newman, D. A. \& Roth, P. L. (2006). How important are job attitudes? Meta-analytic comparisons of integrative behavioral outcomes and time sequences. Academy of Management Journal, 49(2), 305-325. 
Heizer, J., Render, B. \& Munson, C. (2017). Operational management: sustainability and supply chain management. Harlow: Pearson.

Hsu, P. F., Yen, H. R. \& Chung, J. C. (2015). Assessing ERP post-implementation success at the individual level: Revisiting the role of service quality. Information \& Management, 52, 925-942.

IBM SPSS. (2018). IBM Statistical Package for Social Sciences. Seattle, WA: IBM.

Impact Rx. (2016). Impact Rx. http://impactrx.co.za/ Date of access: December 2017.

International Organisation for Standards (ISO). (2018). Defining "Quality". https://www.iso.org/ Date of access: 10 June 2018.

McDonald, M., Payne, A. \& Frow, P. (2011). Marketing plans for services: A complete guide. New York, NY: Wiley.

Mehralian, G., Babapour, J. \& Peiravian, F. (2016). Distributor-retailer interface in pharmaceutical supply chain: service quality measurement scale. Iranian Journal of Pharmaceutical Research, 15(4), 973-982.

Meyer, C. \& Schwager, A. (2007). Customer experience. Harvard Business Review, 85(2), 116-126.

Naidoo, K. (2011). Stress management and its impact on work performance of educators in public schools in KwaZulu-Natal. (Thesis - PhD). Potchefstroom: North-West University.

Niaz, A., Muhammad Usman, A., Abdul, R. \& Leigh, S. (2009). Development of a service quality scale for pharmaceutical supply chains. International Journal of Pharmaceutical and Healthcare Marketing, 1, 26-45.

Parasuraman, A., Zeithaml, V. A. \& Berry, L. L. (1985). A conceptual model of service quality and its implications for future research. The Journal of Marketing, 10, 41-50.

Parasuraman, A., Zeithaml, V. A. \& Berry, L. L. (1988). Servqual: A multiple-item scale for measuring consumer perceptions of service quality. Journal of Retailing, 64(1), 14-40.

Pretorius, D. (2011). The impact of the implementation of single exit pricing for pharmaceuticals in South Africa. (Dissertation: MBA). Johannesburg: University of the Witwatersrand.

Putit, L., Karim, N. F. A. \& Zainuddin, N. (2011). Investigating the relationship between service quality and customer satisfaction: An empirical perspective on pharmaceutical healthcare sector. (In: Business, Engineering and Industrial Applications (ICBEIA), 2011 International Conference on organised by: IEEE. p. 147-152).

Ramamoorthy, R., Gunasekaran, A., Roy, M., Rai, B. K. \& Senthilkumar, S. A. (2018). Service quality and its impact on customers' behavioural intentions and satisfaction: an empirical study of the Indian life insurance sector. Total Quality Management \& Business Excellence, 29(7-8), 834-847.

South African Health Products Regulatory Agency (SAHPRA). (2018). https://www.sahpra.org.za/ Date of access: 10 June 2018.

South Africa (SA). (1965). The Medicines and Related Substances Act (Act 101 of 1965). Pretoria: State printers.

South African Pharmacy Council (SAPC). (2018). South African Pharmacy Council. http://www.pharmcouncil.co.za/B_Statistics.asp Date of access: December 2017.

Van den Heever, A. (2003). Administered Price \& Health: A report for National Treasury. http://www.treasury.gov.za/publications/other/epir/health.pdf Date of access: 10 June 2018.

Van Heerden, J. (2010). Customer Service at a private hospital in the North-West Province. (Dissertation MBA). Potchefstroom: North West University.

Wicks, A. M. \& Roethlein, C. J. (2009). A satisfaction-based definition of quality. Journal of Business \& Economic Studies, 15(1), 82-97.

Williams, B., Onsman, A. \& Brown, T. (2010). Exploratory factor analysis: A five-step guide for novices. Australasian Journal of Paramedicine, 8(3), 1-13.

Wilson, A., Zeithaml, V. A., Bitner, M. J. \& Gremler, D. D. (2012). Services marketing: Integrating customer focus across the firm. New York, NY: McGraw Hill.

Wirtz, J. \& Bateson, J. E. (1999). Consumer satisfaction with services: integrating the environment perspective in services marketing into the traditional disconfirmation paradigm. Journal of Business Research, 44(1), 55-66.

Woods, S. A., Poole, R. \& Zibarras, L. D. (2012). Employee absence and organisational commitment: Moderation effects of age. Journal of Personnel Psychology, 11(4), 199-203.

Zeithaml, V. A., Parasuraman, A. \& Berry, L. L. (1990). Delivering quality service: Balancing customer perceptions and expectations. New York, NY: Simon and Schuster.

Ziemba, E. \& Obłąk, I. (2013). Critical success factors for ERP systems implementation in public administration. Interdisciplinary Journal of Information, Knowledge \& Management, 8, 1-19. 